\title{
(- axteax \\ ( OPEN ACCESS \\ Granulomatosis with polyangiitis in a patient with biopsy-proven IgG4-related pulmonary disease and coincident small cell lung cancer
}

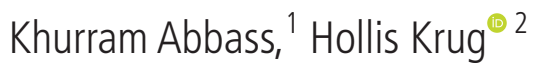

'Department of Medicine, Regional Medical Center, San Jose, California, USA

${ }^{2}$ Rheumatology (111R), Minneapolis VA HCS, Minneapolis, Minnesota, USA

\section{Correspondence to Dr Hollis Krug, hollis.krug@va.gov}

Accepted 6 February 2019

\section{Check for updates}

(C) BMJ Publishing Group Limited 2019. Re-use permitted under CC BY-NC. No commercial re-use. See rights and permissions. Published by BMJ.

To cite: Abbass K, Krug H. BMJ Case Rep 2019:12:e226280. doi:10.1136/bcr-2018226280

\section{SUMMARY}

Granulomatosis with polyangiitis (GPA) was diagnosed in a patient with a 16-month history of IgG4related lung disease that spontaneously became asymptomatic. Cytoplasmic antineutrophil cytoplasmic antibody (ANCA) was positive at the time of diagnosis of IgG4-related disease (IgG4-RD), but there was no vasculitis or kidney disease. Sixteen months later he developed rapidly progressive glomerulonephritis that responded to cyclophosphamide treatment. While undergoing treatment for GPA, he was found to have a lung mass identified as small cell lung cancer. This mass was present at the time of the lgG4RD diagnosis. GPA can be confused with IgG4-RD histologically and they rarely coexist. ANCA antibodies are primarily $\lg G 4$ subclass. IgG4-RD has been associated with cancer and may improve prognosis. We speculate that this patient may have had small cell lung cancer that incited an IgG4 predominant immune response with coexistent ANCA antibodies that eventually resulted in GPA. Immunosuppressive treatment of GPA likely accelerated the progression of the lung cancer.

\section{BACKGROUND}

It is important to recognise the difficulty of distinguishing IgG4-related disease (IgG4-RD) in the lung from granulomatosis with polyangiitis (GPA). The pathophysiology of IgG4-RD is not known and may be paraneoplastic or develop as an immune response against cancer in some individuals. Cancer surveillance should be considered after IgG4-RD diagnosis.

\section{CASE PRESENTATION}

A 64-year-old man with a history of IgG4 lung disease presented to rheumatology clinic for routine follow-up with 3 weeks of progressive productive cough, haemoptysis, myalgias, arthralgias and weakness, with fever and chills for 2-3 days. He was admitted for further evaluation. A diagnosis of IgG4 lung disease had been made at an outside facility 16 months prior to admission. Initial presentation at that time was haemoptysis and CT of the chest was notable for multiple lung masses with increased metabolic activity on positron emission tomography CT. He underwent two non-diagnostic CT-guided core biopsies of the lung masses in the left lower lobe followed by video-assisted thoracic surgery to obtain a $4 \mathrm{~cm}$ wedge biopsy of the right lower lobe. The pathological specimen was evaluated at a centre known internationally for expertise in IgG4-RD and according to the report demonstrated 'a plasma-cell rich nodular fibroinflammatory lesion with endothelialitis and marked increase in IgG4 + cells (>30/high power field $[\mathrm{HPF}])$, heavy chronic inflammatory infiltrates and marked fibrosis. The inflammatory cells were mainly comprised of plasma cells mixed with some lymphocytes and there was also prominent vascular involvement characterized by intimal inflammation without necrosis. Fibrotic areas showed active, whorled fibroblastic proliferation as well as collagen deposition. The visceral pleura wasdiffusely thickened due to organizing fibrinous exudate, granulation tissue and some collagen fibrosis. The underlying lung tissue showed patchy foci of organizing pneumonia and nonspecific inflammatory infiltrates. No granulomas. No evidence for malignancy. Constellation of the above histopathological findings is most suggestive of IgG4-related lung disease. Indeed, the IgG4 immunostain supported this impression in that there were numerous IgG4-positive plasma cells among the IgG-positive cells with increased IgG4/IgG ratio greater than $10 \%$ as well as with absolute number greater than $30 / \mathrm{HPF}$ in hot spots (Mayo score 3) (figure 1). These findings were consistent with IgG4 related lung disease based on comprehensive diagnostic criteria for IgG4-RD with the exception of the IgG4/ IgG ratio of $>10 \%$ since these criteria require a ratio $>40 \% .{ }^{1}$ Laboratory studies were remarkable for elevated IgG4 $>135 \mathrm{mg} / \mathrm{dL}$, positive ANCA and anti-proteinase 3 (PR3). On referral to our facility 13 months prior to this admission, repeat laboratory studies found a positive c-ANCA 1:160 with a positive confirmatory PR3 antibody of 15 (positive >9). Haemoptysis resolved spontaneously without specific treatment. There was partial resolution of the lung masses by serial CT scans (figure 2). There was no other organ system involvement at that time. IgG4 remained elevated at $153 \mathrm{mg} / \mathrm{dL}$.

On admission, his temperature was $38.1^{\circ} \mathrm{C}$, pulse was 105 beats/min, respiratory rate was $20 / \mathrm{min}$, blood pressure was $100 / 70 \mathrm{~mm} \mathrm{Hg}$ and oxygen saturation was $90 \%$ on room air. He was 




Figure 1 Pathology from initial right lower lobe lung wedge resection in 2011 (A-G) and from left upper lobe biopsy in 2012 (H-M): (A) storiform fibrosis and lymphocytoplasmic inflammation, (B) highpower view of plasma cells and fibrosis, (C) IgG immunostain, (D) IgG4 immunostain, (E) leucocytoclastic vasculitis, (F) lymphocytic endothelialitis, (G) obliterative phlebitis, $(\mathrm{H})$ small cell carcinoma low-power view, (I) small cell carcinoma high-power view, (J) small cell carcinoma oil-immersion view with mitotic figures, (K) small cell carcinoma - chromogranin immunohistochemical stain, (L) small cell carcinoma - pankeratin immunohistochemical stain and (M) small cell carcinoma - synaptophysin immunohistochemical stain.

in moderate respiratory distress. His right eye was mildly injected. The pharynx was clear. There was diffuse tender cervical lymphadenopathy. No jugular venous distension or bruit was noted. He had a grade II/VI systolic murmur at right upper sternum. Lung exam revealed diffuse crackles and decreased breath sounds at both bases. The abdominal exam was normal. There was $1+$ oedema in the lower extremities.

\section{INVESTIGATIONS}

Admission laboratory results are shown in table 1. Chest CT showed marked interval increase in diffuse opacities in the lungs, some coalesced into mildly irregular marginated nodules and masses (figure 1).

He underwent renal biopsy and bronchoalveolar lavage, which revealed copious blood in the right main stem bronchus and right middle lobe. Following bronchoscopy he required $100 \%$ high-flow oxygen and intubation for hypoxic respiratory failure. Renal biopsy was read as diffuse acute necrotising/ crescentic glomerulonephritis, pauci-immune type.

\section{TREATMENT}

Broad-spectrum antibiotics were begun for presumed infection. He was treated with intravenous methylprednisone $1 \mathrm{~g} /$ day for 3 days,

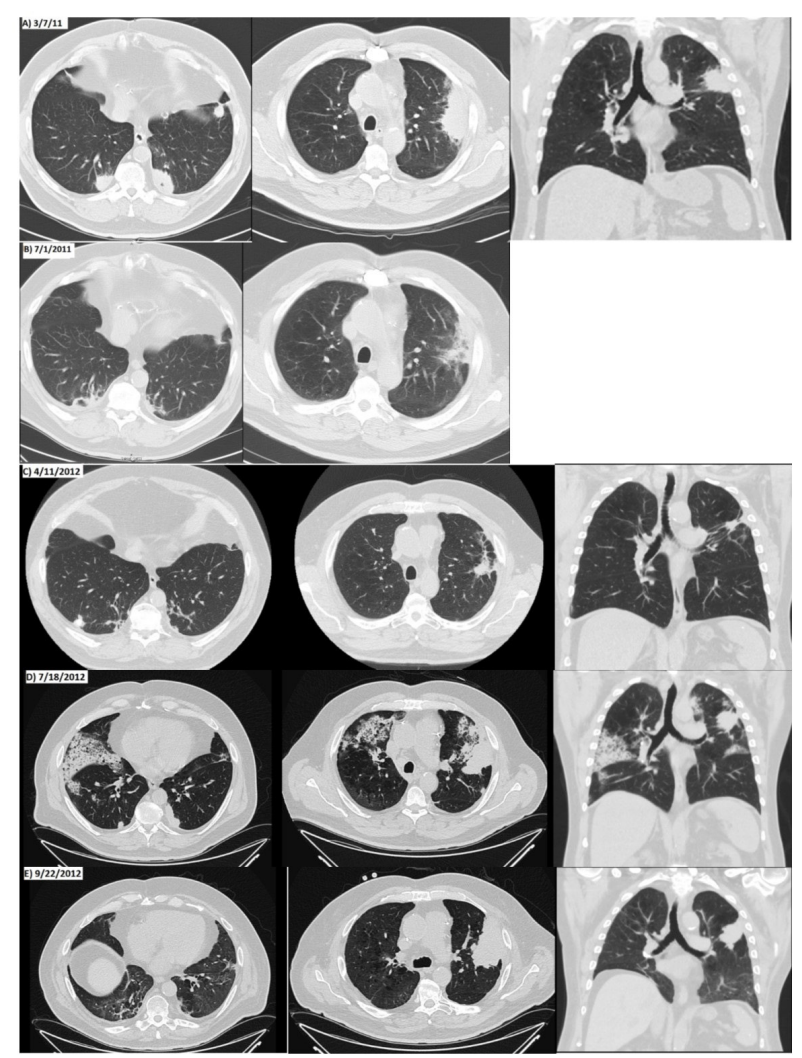

Figure 2 Sequential chest CT scans from the time of: (A) initial lgG4related diagnosis, (B and $C$ ) showing partial resolution of lower lobe masses and left upper lobe mass without treatment, (D) diffuse alveolar haemorrhage and enlargement of the left upper lobe mass at the time of diagnosis of GPA and (E) resolution of all, but the left upper lobe mass after treatment for GPA. GPA, granulomatosis with polyangiitis.

pulse intravenous monthly cyclophosphamide and seven cycles of plasmapheresis. He subsequently required haemodialysis. After 2 weeks he was extubated and made a slow recovery. After 1 month,

\begin{tabular}{ll}
\hline Table 1 & The patient's laboratory findings on admission \\
\hline Laboratory study & Result \\
\hline WBC & $10.9 \times 10^{9} / \mathrm{L}$ \\
\hline Haemoglobin & $97 \mathrm{~g} / \mathrm{L}$ \\
\hline Haematocrit & $29.7 \%$ \\
\hline Platelets & $348 \times 10^{9} / \mathrm{L}$ \\
\hline AST & $30 \mathrm{U} / \mathrm{L}$ \\
\hline ALT & $32 \mathrm{U} / \mathrm{L}$ \\
\hline BUN & $43 \mathrm{mg} / \mathrm{dL}$ \\
Creatinine & $3.7 \mathrm{mg} / \mathrm{dL}$ \\
\hline C-reactive protein & $150.00 \mathrm{mg} / \mathrm{dL}$ (normal range $0-3.0 \mathrm{mg} / \mathrm{L}$ ) \\
Sedimentation rate & $>120 \mathrm{~mm} / \mathrm{hour}$ \\
\hline IgG4 & $289 \mathrm{mg} / \mathrm{dL}$ \\
\hline C-ANCA & $1: 640$ (confirmatory PR3 not done) \\
\hline Urinalysis: & Protein $200 \mathrm{mg} / \mathrm{dL}$ \\
\hline & RBC: $148 / \mathrm{hpf}$ \\
\hline & WBC: $85 / \mathrm{hpf}$ \\
\hline & Negative nitrates \\
\hline
\end{tabular}

ALT, aspartate aminotransferase; AST, alanine aminotransferase; BUN, blood urea nitrogen; c-ANCA, cytoplasmic-antineutrophil cytoplasmic antibody; PR3, proteinase 3; RBC, red blood cell; WBC, white blood cell. 
he was discharged home with oxygen. One month later, he was significantly improved, his creatinine was $3.6 \mathrm{mg} / \mathrm{dL}$ and he no longer required dialysis.

\section{OUTCOME AND FOLLOW-UP}

Two months later, because of the continued dyspnoea on exertion repeat chest CT was done and revealed a left upper lobe mass that was increased in size compared with 2 months earlier. This mass was located in the same area as one of the initial masses identified at the time of IgG4-RD, but had never been biopsied. Subsequent biopsy revealed small cell carcinoma. The patient underwent one cycle of chemotherapy, but declined further treatment. He received 6 monthly cyclophosphamide infusions for GPA then transitioned to maintenance azathioprine. Six months later he remained on $2 \mathrm{~L} / \mathrm{min}$ of home oxygen, but did not require dialysis. He succumbed to the small cell lung cancer 1 year after this admission.

\section{DISCUSSION}

Granulomatosis with polyangiitis (GPA, previously known as Wegener's granulomatosis) is one of the ANCA-associated vasculitides (AAV), which involves the upper and lower respiratory tract and kidneys. ${ }^{2}$ It is a multisystem disorder characterised by necrotising granulomatous inflammation and pauci-immune vasculitis. Nasal discharge, sinusitis and epistaxis are common. Lungs are involved in 90\% of patients. ${ }^{3}$ Arthralgias, cutaneous vasculitis and mononeuritis or polyneuritis can develop. More than $70 \%$ of patients have renal involvement with necrotising glomerulonephritis. ${ }^{4}$ There is a strong association with antibodies to PR3, a constituent of neutrophilic azurophilic granules. Antibodies to c-ANCA, which targets PR3, has good specificity for the diagnosis of GPA, although the sensitivity is not as good. ${ }^{4}$ The presence of such antibodies is a strong indicator for a diagnosis of GPA, but should not substitute for tissue diagnosis. ${ }^{5}$ The differential diagnosis includes microscopic polyangiitis and Churg-Strauss vasculitis. The use of aggressive immunotherapy in this disease is critical as survival in patients with untreated GPA is very poor with up to $90 \%$ of patients dying within 2 years from pulmonary or renal failure. Malignancies have been associated with AAV, but they are thought to be related to cytotoxic immunosuppressive therapy and generally occur years after the diagnosis of AAV.

Our patient carried a diagnosis of IgG4 related lung disease that was established by open lung biopsy 16 months before his current presentation. Although the pathological diagnosis was established by a reputable laboratory, it is possible that the findings were misinterpreted and that the overlapping characteristics between GPA and IgG4-RD led to an inaccurate diagnosis. The prevalence of IgG4 + cells in GPA tissues may be increased. In a recent study done at the Mayo Clinic, of 26 patients confirmed as GPA by a thorough clinical and pathological assessment, eight patients revealed increased IgG4 + cells $(>30 / \mathrm{HPF}$ and $>40 \%$ in IgG4+/IgG + ratio). ${ }^{7}$ Interestingly, ANCA autoantibodies have a predominance of IgG1 and IgG4 subclasses suggesting they may be related to a hypersensitivity reaction. ${ }^{8}$

IgG4-RD is an immune-mediated lymphoproliferative disorder characterised by lymphoplasmacytic infiltrates containing IgG4 + plasma cells in the affected organs and hyper IgG4 globulinemia. ${ }^{9}$ Two major presentations of this condition are type 1 autoimmune pancreatitis (IgG4-related pancreatitis) and sialadenitis, however, involvement of other organs has been reported. Several patterns of lung involvement have been described. $.^{10-12} \mathrm{~Pa}-$ tients often present with subacute development of a mass in the affected organ or diffuse enlargement of an organ. Multiple organs are affected in $60 \%$ to $90 \%$ of patients with IgG4-RD. Cases of cholangitis, dacroadenitis, retroperitoneal fibrosis, mediastinal fibrosis, tubulointerstitial nephritis, interstitial pneumonitis hepatitis, thyroiditis, prostatitis and gastritis have been reported as well. ${ }^{13}$ This disease generally responds well to immunosuppression, but can resolve spontaneously.

Our patient had IgG4 lung disease characterised by diffuse pulmonary nodules and haemoptysis. IgG4 related pulmonary disease may be asymptomatic or present with cough, haemoptysis, dyspnoea, pleurisy or chest pain. As Della-Torre et $a l^{14}$ reported previously in a review of six patients with biopsy-proven IgG4-RD and positive ANCA, AAV in patients with established IgG4-RD presented with systemic manifestations beyond the ear/nose/throat region. These observations suggest that patients with IgG4-RD and positive ANCA might be more at risk of developing a systemic form of AAV, raising the possibility that ANCA in these patients might sustain an underlying vasculitic process rather than being primarily linked to IgG4RD. Indeed, both myeloperoxidase (MPO)- and PR3-ANCA of patients with AAV have been previously shown to induce respiratory burst, calcium flux and degranulation of neutrophils, thus directly contributing to the pathophysiology of AAV. It is known that IgG4 ANCA elicit a more vigorous generation of reactive oxygen species in vitro compared with those elicited by IgG1 ANCA. ${ }^{15}$ These authors speculate that the prominent IgG1 and IgG4 production that is characteristic of IgG4-RD might foster the development of AAV in some patients with an appropriate genetic background. ${ }^{14}$

The diagnosis of GPA in our patient was established on the basis of renal biopsy, pulmonary haemorrhage and high-titer PR3-ANCA antibodies. Although he carried a diagnosis of IgG4 related lung disease and previously had positive c-ANCA (and no clinical concern for AAV), he had been asymptomatic for 14 months and sequential urinalyses showed no abnormality till the day of admission. The most common renal involvement in IgG4-RD is tubulointerstitial nephritis, ${ }^{16}$ however, mild mesangioproliferative glomerulonephritis, membranous nephropathy and focal segmental endocapillary hypercellularity have also been reported. ${ }^{13}$ Given the usual poor prognosis of patients with GPA in the absence of treatment, it is likely that if GPA was present at the time of open lung biopsy, it was in early stages that progressed over time to be symptomatic.

This case is unique in that although both AAV and IgG4-RD disease have been associated with malignancy, this may be the only case of all three diseases occurring concurrently. We believe that our patient may have developed GPA on the background of IgG4-RD that may have developed as an immune response to an occult malignancy, which in retrospect was present on the original chest CT. The pathophysiology of IgG4 disease is complex and is thought to be partly due to altered interaction between the innate and adaptive immune system characterised by $\mathrm{T}$ helper cell type 2-dominated cytokine production, increased IgG4 production and increased regulatory $\mathrm{T}$ cells. ${ }^{17}$ Likewise the pathogenesis of AAV is attributed to a triggering environmental or infectious exposure followed by pro-inflammatory signals and triggering of the innate immune system and activation of the adaptive immune system in genetically susceptible people. However, this may trigger a break in immune tolerance and result in the development of autoimmunity and reduced regulatory $\mathrm{T}$ cells. The pathophysiological differences between these two diseases suggests that one may be an attempt to regulate the other. There may be a higher incidence of malignancies in patients with IgG4-RD disease. ${ }^{18}$ One hypothesis about 
the association of IgG4 disease and malignancy is that the IgG4 response arises as a paraneoplastic response and is hypothesised to improve the prognosis in non-small cell lung cancer. ${ }^{8}$ Checkpoint inhibitors now commonly used to treat malignant disease work by activating $\mathrm{T}$ cells specific for tumour antigens and by reducing regulatory $\mathrm{T}$ cell inhibition of the immune response, often resulting in autoimmune-type side effects. ${ }^{19}$ It is interesting to speculate that the presence of a persistent left upper lobe mass in our patient that improved with IgG4 disease, but worsened after immunosuppression, might reflect a native immunologic anti-tumour response followed by loss of immunologic surveillance with immunosuppression due to chemotherapy.

Finally, it is possible that this was the coexistence of two rare autoimmune diseases in the same patient over a period of 2 years with a coincident, but unrelated malignancy.

\section{Learning points}

The presence antineutrophil cytoplasmic antibody autoantibodies in concert with a pathological diagnosis of IgG4-related disease (IgG4-RD) should prompt close follow-up for symptoms and signs of granulomatosis with polyangiitis (GPA). In the rare patient with both IgG4-RD pulmonary disease and pulmonary GPA, screening for lung cancer would be a good practice.

- Even expert pathological evaluation can confuse lgG4-RD with GPA.

- A better understanding of the relationship and pathophysiology of malignancy, IgG4-associated diseases and GPA is needed.

Contributors HK recognised the importance of this case, cared for the patient, consulted with consultants during and after the patient's illness, acquired much of the necessary information and finalised the publication. KA collected the patients clinical information and drafted the original article.

Funding This work was supported by the United States Department of Veterans Affairs.

Competing interests None declared.

Patient consent for publication Next of kin consent obtained.

Provenance and peer review Not commissioned; externally peer reviewed.

Open access This is an open access article distributed in accordance with the Creative Commons Attribution Non Commercial (CC BY-NC 4.0) license, which permits others to distribute, remix, adapt, build upon this work non-commercially, and license their derivative works on different terms, provided the original work is properly cited and the use is non-commercial. See: http://creativecommons.org/ licenses/by-nc/4.0/

\section{REFERENCES}

1 Umehara H, Okazaki K, Masaki Y, et al. Comprehensive diagnostic criteria for lgG4related disease (IgG4-RD), 2011. Mod Rheumatol 2012;22:21-30.

2 Yunt ZX, Frankel SK, Brown KK. Diagnosis and management of pulmonary vasculitis. Ther Adv Respir Dis 2012:6:375-90.

3 Jolly M, Molta C, Hoffman G. Wegener's granulomatosis: pitfalls in the management of pulmonary disease: A case of Wegener's granulomatosis with a hilar mass. $J$ Rheumatol 2000;27:2511-2

4 Gaskin G, Pusey CD. Systemic vasculitis. Davison AM, ed. Oxford textbook of clinical nephrology. Oxford: Oxford University Press, 1998.

5 Savige J, Davies D, Falk RJ, et al. Antineutrophil cytoplasmic antibodies and associated diseases: a review of the clinical and laboratory features. Kidney Int 2000;57:846-62.

6 Shang W, Ning Y, Xu X, et al. Incidence of cancer in ANCA-associated vasculitis: A meta-analysis of observational studies. PLoS One 2015;10:e0126016.

7 Chang SY, Keogh K, Lewis JE, et al. Increased IgG4-positive plasma cells in granulomatosis with polyangiitis: a diagnostic pitfall of lgG4-Related Disease. Int J Rheumatol 2012;2012:1-6.

8 Brouwer E, Tervaert JW, Horst G, et al. Predominance of IgG1 and IgG4 subclasses of anti-neutrophil cytoplasmic autoantibodies (ANCA) in patients with Wegener's granulomatosis and clinically related disorders. Clin Exp Immunol 1991;83:379-86.

9 Cheuk W, Chan JK. IgG4-related sclerosing disease: a critical appraisal of an evolving clinicopathologic entity. Adv Anat Pathol 2010;17:303-32.

10 Inoue D, Zen Y, Abo H, et al. Immunoglobulin G4-related lung disease: CT findings with pathologic correlations. Radiology 2009;251:260-70.

11 Zen Y, Inoue D, Kitao A, et al. IgG4-related lung and pleural disease: a clinicopathologic study of 21 cases. Am J Surg Pathol 2009;33:1886-93.

12 Campbell SN, Rubio E, Loschner AL. Clinical review of pulmonary manifestations of IgG4-related disease. Ann Am Thorac Soc 2014;11:1466-75.

13 Saeki T, Nishi S, Imai N, et al. Clinicopathological characteristics of patients with IgG4related tubulointerstitial nephritis. Kidney Int 2010;78:1016-23.

14 Della-Torre E, Lanzillotta M, Campochiaro C, et al. Antineutrophil cytoplasmic antibody positivity in IgG4-related disease: A case report and review of the literature. Medicine 2016;95:e4633.

15 Holland M, Hewins P, Goodall M, et al. Anti-neutrophil cytoplasm antibody IgG subclasses in Wegener's granulomatosis: a possible pathogenic role for the lgG4 subclass. Clin Exp Immunol 2004;138:183-92.

16 Murashima M, Tomaszewski J, Glickman JD. Chronic tubulointerstitial nephritis presenting as multiple renal nodules and pancreatic insufficiency. Am J Kidney Dis 2007:49:e7-e10

17 Umehara H, Nakajima A, Nakamura T, et al. IgG4-related disease and its pathogenesis-cross-talk between innate and acquired immunity. Int Immuno 2014:26:585-95

18 Yamamoto M, Takahashi H, Tabeya T, et al. Risk of malignancies in IgG4-related disease. Mod Rheumatol 2012;22:414-8.

19 Pardoll DM. The blockade of immune checkpoints in cancer immunotherapy. Nat Rev Cancer 2012;12:252-64.

Copyright 2019 BMJ Publishing Group. All rights reserved. For permission to reuse any of this content visit

https://www.bmj.com/company/products-services/rights-and-licensing/permissions/

BMJ Case Report Fellows may re-use this article for personal use and teaching without any further permission.

Become a Fellow of BMJ Case Reports today and you can:

- Submit as many cases as you like

- Enjoy fast sympathetic peer review and rapid publication of accepted articles

- Access all the published articles

- Re-use any of the published material for personal use and teaching without further permission

For information on Institutional Fellowships contact consortiasales@bmjgroup.com

Visit casereports.bmj.com for more articles like this and to become a Fellow 